\title{
O Primeiro Estruturalismo: Método de Pesquisa para as Ciências da Gestão(1)
}

\author{
Hermano Roberto Thiry-Cherques
}

\begin{abstract}
RESUMO
O objetivo deste texto é o exame das idéias centrais que conformam o estruturalismo como abordagem metodológica às ciências sociais e, em especial às ciências da gestão. Nele discutimos as definições básicas dos conceitos que orientaram o desenvolvimento do estruturalismo original e procuramos explicitar os passos essenciais na aplicação do método estruturalista às pesquisas em ciências da gestão. Concluímos com uma análise das críticas à abordagem estruturalista.
\end{abstract}

Palavras-chave: método; estruturalismo; administração; pesquisa; ciências da gestão.

\section{Abstract}

The purpose of this paper is to assess the central ideas of the structuralism methodological approach to social sciences, chiefly to management sciences. Definitions of the concepts concerned to original structuralism are discussed. Based on this discussion an attempt is made to explain the essential steps to apply the structuralism method on management sciences researches. We conclude the paper with an assessment of main criticism against structuralism approach.

Key words: method; structuralism; administration; research; management sciences. 


\section{INTRODUÇÃO}

O estruturalismo é uma construção teórica iniciada pelo etnólogo Claude LéviStrauss. A partir das suas postulações, o entendimento estruturalista ganhou corpo e se desdobrou em dois planos. O primeiro fundamentou uma das correntes filosóficas que animaram a segunda metade do século XX. O segundo irradiou sua epistemologia para os mais diversos campos das ciências humanas e sociais. Dentre esses campos figura o das ciências da gestão, entendida como compreendendo os estudos organizacionais e os estudos administrativos.

Como movimento filosófico, o estruturalismo tem um papel decisivo na trajetória que envolve o embate entre o positivismo lógico, a fenomenologia, a fenomenologia existencial e o historicismo. Embora o corpo teórico do primeiro estruturalismo tenha perdido homogeneidade, os seus preceitos iniciais continuam a ser uma das fontes da problematização sobre as quais se verte a ontologia e a gnosiologia contemporâneas.

Enquanto método, processo organizado, lógico e sistemático de pesquisa das ciências humanas e das ciências sociais, o estruturalismo tem fortuna variada. Em alguns ramos, como o da psicologia, o da lingüística e o da crítica, ocupa um papel central. Em outros, ou bem foi absorvido pelas linhas metodológicas posteriores ou foi incorporado apenas fragmentariamente. Nas ciências da gestão tem pouca influência direta. Mas os seus desenvolvimentos, como o estruturalfuncionalismo e o estruturalismo genético, embasam uma gama significativa de estudos e pesquisas. É o caso do marco de inflexão teórico representado por trabalhos como os de Amitai Etzioni (1967), ou de Peter Blau (1970), ou de contribuições metodológicas de grande impacto, como as de Talcott Parsons (1960), Michel Foucault $(1972,1979)$ e Pierre Bordieu $(2001 ; 2002)$.

A perspectiva estruturalista propõe o abandono do exame particular dos objetos a que se consagra. Estuda as estruturas subjacentes ao organizar e ao administrar, formadas pelos elementos que os caracterizam enquanto traços inerentes ao espírito humano. Desconsidera as organizações e as formas de administrar, tomadas como manifestações de outras coisas - como segmento social, agente econômico, ator político, etc. - que não elas mesmas. Seu propósito é a constituição de modelos arquetípicos de todas as organizações e de todas as formas de organizar.

Nem sempre o método estruturalista e os métodos que derivam do estruturalismo são facilmente entendidos pelos pesquisadores. Esta dificuldade é observada no embasamento de dissertações, de teses e de pesquisas aplicadas. Tem raízes no 
desconhecimento dos preceitos elementares da epistemologia estruturalista original, no distanciamento entre o estruturalismo e os métodos predominantes no campo da administração, geralmente afiliados ao positivismo lógico, nas barreiras idiomáticas e, principalmente, na carência de exposições sobre o emprego prático do método estruturalista ajustado ao campo das ciências da gestão.

Neste artigo procuramos contribuir para a superação desta dificuldade, mediante a apresentação sistemática dos passos metodológicos do primeiro estruturalismo, isto é, dos passos dos quais derivou a maioria, se não a totalidade das metodologias estruturalistas dos diversos ramos das ciências humanas e sociais.

\section{Idélas Centrais do Estruturalismo}

O estruturalismo nasceu de uma circunstância recorrente nas pesquisas empíricas. É uma tentativa de superação de um problema que aflige grande número de estudiosos no campo social: o da multiplicidade infinita de situações díspares. Em termos objetivos, essa dificuldade se expressa da seguinte forma: quanto maior o rigor no detalhamento da pesquisa, mais os dados e informações coligidos parecem descrever uma situação única, só verificável naquele espaço e naquele momento específicos.

Esta diversidade, esta riqueza de situações, geralmente se revela um transtorno para os que realizamos pesquisas empíricas. É que quando utilizamos o processo indutivo, partindo dos dados particulares (fatos, experiências, enunciados empíricos) e, por meio de uma seqüência de operações cognitivas, procuramos chegar a conceitos mais gerais, indo dos efeitos à causa, das consequiências ao princípio, da experiência à teoria, isto é, quando procuramos encontrar pontos comuns entre aquela situação e outras que conhecemos, somos compelidos a limitar de tal maneira o número de coincidências comprováveis que terminamos por discorrer sobre o óbvio. Por outro lado, quando optamos por analisar os dados e informações a partir de alguma premissa teórica (processo dedutivo), somos constrangidos a deixar de lado a originalidade e a diversidade das particularidades reveladas pela investigação.

Os caminhos de escape deste dilema não são muitos. A fenomenologia, o pensamento dialético e outras, poucas, fontes epistemológicas oferecem soluções e saídas. A maioria envolve um forte aparato de abstração teórica, de sorte que, ao tentarmos ser fieis à realidade sem perder o rigor científico, nos vemos tolhidos a optar entre um discurso infinito e um enunciado sobre o imaginário. 


\section{O Percurso de Lévi-Strauss}

Foi esta a dificuldade com que se deparou o etnólogo francês Claude LéviStrauss. Preso entre instrumental metodológico da sua época e a realidade concreta observada, ele se viu obrigado a decidir entre duas linhas de conduta. Ou bem obedecia aos cânones estabelecidos da ciência e desprezava o que havia constatado, ou bem, e esta foi a sua escolha, se dedicava à construção de uma base teórica que permitisse a superação do dilema.

O estruturalismo, que sofre influências do pensamento dialético, da fenomenologia existencial e até da geologia (Lévi-Strauss, 1971), mas que nasce das pesquisas de campo e não do raciocínio especulativo, é uma tentativa de reconciliar a teoria com a prática. Lévi-Strauss procurou uma ponte entre o lógico e o empírico, um fundamento que pudesse dar conta da diversidade do mundo, um instrumental que fosse deduzido, ele também, do real. Algo que não fosse a simples descrição do empírico imediato, que não resvalasse para o devaneio, para a pura abstração. Que fosse uma teoria do possível.

A base científica criada por Lévi-Strauss, se propõe justamente isto: desenvolver uma teoria do logicamente possível, construída a partir do real concreto. É fruto de uma convicção teórica, da insatisfação e do acaso. A noção teórica foi apreendida de Marcel Mauss (1968), um antropólogo de grande envergadura, e que sustentava ser "a vida social um mundo de relações simbólicas" (1973a). A insatisfação procedia do contraste entre o verificável na vida social, notadamente na vida das sociedades primitivas, e os ensinamentos que daí se podiam tirar. O acaso envolveu as peripécias da derrota francesa no começo da Segunda Guerra Mundial e a comunidade de intelectuais refugiados em Nova York, tempo e lugar em que Lévi-Strauss tem acesso aos progressos teóricos da lingüística estruturalista de Saussure.

Freqüentando os seminários de outro exilado, Roman Jakobson (1973), pesquisador e teórico da lingüística estruturalista, Lévi-Strauss aprendeu que enquanto a filologia clássica considerava que a língua era uma espécie de espelho da realidade (teoria mimética), entendendo que cada vocábulo possuía uma relação natural com a coisa que refere, Saussure se preocupou com a sistematização dos sinais, vindo a criar uma nova ciência, a semiologia, baseada na teoria da arbitrariedade do signo. Uma ciência segundo a qual as relações entre os vocábulos e o mundo se estabelecem não por leis imanentes da natureza, mas por operações derivadas de relações estruturais profundas do espírito humano (Teixeira, 1998, p. 35).

O ponto de partida da lingüística de caráter estruturalista é a idéia de que a 
linguagem não pode estar limitada às relações entre as palavras e as coisas (Hughes \& Sharrock, 1999, p. 418). De modo que a forma correta de interpretar a linguagem é como sistema diferenciado, em que as unidades lingüísticas devem ser caracterizadas pelos papéis que desempenham e identificadas pelo contraste que apresentam entre si, deixando de lado a função referencial. O problema do signo se concentra na relação entre o significado (o conceito) e o significante (a imagem acústica). O foco é o da língua (o construído), não o da fala (o dado). Com isto, a linguística se desembaraçou do sujeito que fala, da psicologia do falante, da genealogia dos significados, para se concentrar na logicidade da língua e do discurso (Dosse, 1993, p. 73). As unidades ou elementos lingüísticos formam estruturas subjacentes a qualquer idioma e a qualquer discurso. Formam relações de concordância, de subordinação e de ordem, que constituem estruturas invariantes universais.

Transpostas para o mundo das relações sociais, as premissas do estruturalismo lingüístico permitiram a Lévi-Strauss desenvolver uma construção teórica de superação do contraditório entre a realidade observável e o que pode ser coligido, ordenado e transmitido, entre o concreto e o que pode ser objeto de ciência. A sua proposta é a de:

- considerar não o fenômeno consciente e as relações que mantêm entre si os elementos diretamente observáveis, mas a voltar-se para a estrutura inconsciente - que sustenta e ordena estes elementos e estas relações;

- estudar não mais os elementos, mas, ao contrário, privilegiar a descrição e a análise das relações entre os elementos;

- se concentrar na ordenação destas relações como sistemas inteligíveis, não como invenções do espírito nem como simples abstrações, mas como relações, que ainda que baseadas no empírico, são também racionais, isto é, são passíveis de serem representadas por esquemas lógico-matemáticos;

- se restringir aos sistemas efetivos, isto é, aos sistemas de relações simultâneas em um tempo dado (os sistemas sincrônicos), e abandonar toda a idéia de origem e formação histórica dessas estruturas (a diacronia);

- identificar as leis gerais destes sistemas, seja por indução, seja por dedução lógica.

É munido dessas idéias que Lévi-Strauss declara o programa do primeiro estruturalismo, do que vai desencadear a revolução metodológica de que nos ocupamos agora. 


\section{Estruturas: Significados e Propriedades}

O procedimento metodológico do estruturalismo é orientado pelo entendimento do que vem a ser a estrutura, de suas características e de suas propriedades.

Por definição, uma estrutura é um sistema relacional ou um conjunto de sistemas relacionais, tais como as relações de parentesco, os esquemas de controle de tráfego, os códigos de etiqueta, etc. Uma estrutura é um todo formado de fenômenos solidários. Cada um dos seus elementos depende dos outros e é determinado por sua relação com eles. A alteração, acréscimo ou supressão de um elemento implica acomodação e reajuste na posição dos demais.

É preciso distinguir o conceito de estrutura do de sistema. No campo das ciências da gestão, o conceito de /sistema/ é utilizado pelas abordagens funcionalistas ou funcional-estruturalistas, como, por exemplo, a teoria geral dos sistemas e a da contingência. $\mathrm{O}$ sistema é um modelo dinâmico, descreve a ação de um conjunto de elementos funcionais (entrada, processo, saída, feedback, etc.). Também o termo /estrutura/ é amplamente utilizado. Em geral significa qualquer disposição de elementos. Mas no contexto do estruturalismo, /estrutura/ tem uma definição precisa: a estrutura é um modelo explanatório abstrato, que descreve propriedades relacionais entre elementos (Runciman, 1969, p. 255).

O estruturalismo se distingue de outras correntes de pensamento por tratar os objetos enquanto "posições em sistemas estruturados" e não enquanto "objetos existentes independentemente de uma estrutura". Sistema, estrutura e modelo são termos que muitas vezes se confundem. No estruturalismo a distinção entre eles é imprescindível. Um sistema é um conjunto de entidades mutuamente interrelacionadas e interdependentes, operando juntas em um nível determinado de organização (Caws, 1974, p. 3). Aplicamos o termo sistema para designar o conjunto concreto de elementos harmonicamente funcionais. Já uma estrutura é um conjunto de relações. Não tem o atributo da funcionalidade. Um sistema funciona. Uma estrutura é. As relações estruturais podem ser abstratas, se e quando puramente lógicas, ou podem ser relações concretas, se e quando incorporadas a um sistema.

O estruturalismo não é uma corrente de pensamento que se queira "melhor" do que as demais. O que sustentam os estruturalistas é que a abordagem metodológica que aplicam é adequada a determinados objetos, ao desvelamento de estruturas não aparentes, ocultas sob o que é manifesto e intencional. Não interessa, por exemplo, ao estruturalismo estruturas organizacionais expressas nos organogramas, mas o que subjaz, como inerente à razão humana, sob estas estruturas. 
Enquanto outras formas de pensamento se concentram na elucidação dos sistemas - de como as coisas funcionam - ou focam diretamente fenômenos isolados, a idéia central do estruturalismo é a de que a estrutura - o conjunto de relações - é o determinante na explicação dos objetos psicossociais. Distinguese, portanto, do historicismo, do positivismo lógico e da fenomenologia.

O estruturalismo não nega as condicionantes históricas. Ele só se opõe à história que pretende estudar os elementos isolados, em lugar de tomar consciência dos seus nexos. Tem da história uma noção operacional, não filosófica. Contra o historicismo, Lévi-Strauss (1958, p. 6-8) argumentou que as sociedades não são etapas de um desenvolvimento que chega até hoje (a "lógica hegeliana do progresso"), que o historicismo não considera as diversidades no espaço, as descontinuidades no tempo e que utiliza uma única categoria de compreensão. Contra o pensamento dialético e o historicismo em geral, o estruturalismo descrê que seja possível reconstruir a história dos fenômenos sociais desde seu interior. O estruturalismo aceita que existam causas, relações causais e mudanças, até mesmo de caráter histórico (relações diacrônicas), mas não crê que tais relações sejam determinantes na compreensão do mundo que nos cerca.

Embora também faça uso de técnicas lógico-formais de análise da linguagem, o estruturalismo se afasta da idéia de que o conhecimento possa ser obtido somente pelo esclarecimento conceitual, pelo esclarecimento dos significados dos enunciados. O estruturalismo se diferencia do conceito de estrutura do empiricismo lógico, ao afirmar que a relação precede a seus termos e a forma precede o conteúdo. No estruturalismo não existem elementos primeiros determinantes (elementos isolados). O que há são sistemas de relações entre fenômenos.

O estruturalismo substitui a ênfase atomista dos fenômenos como entidades unívocas e mutuamente independentes pela elaboração de modelos de ordem geral que enfatizam as relações entre os fenômenos. Com isto tira o foco da investigação de qualquer elemento particular. Até mesmo, e principalmente, tira o foco do sujeito e das questões a ele relacionadas, como a subjetividade, o pathos, a liberdade individual, para enfatizar a condição humana, seus limites e restrições inconscientes e os padrões que a conformam. O estruturalismo é uma filosofia sem sujeito.

Outra distinção importante a ser feita é entre a posição original do estruturalismo e a das correntes de pensamento dele derivadas. O primeiro estruturalismo examina as estrutura em um momento determinado. Distingue a sincronia - o estado do campo de estudo como sistema de elementos - da diacronia - a sucessão dos estados sincrônicos. A análise sincrônica é a análise de um estado. A análise diacrônica é a análise no tempo de elementos concretos (não história); de estruturas 
que se sucedem. O primeiro estruturalismo se atém às estruturas sincrônicas, aos modelos de vida social que se explicam como invariantes no tempo e no espaço.

A oposição estruturalista entre os elementos é referida a uma condição estática, dentro de um sistema de relações de elementos presentes. Enquanto a hegeliana, por exemplo, é dinâmica. É referida aos elementos contraditórios que levam a um sistema distinto, onde estes contraditórios já não mais existem isoladamente (Kronenfeld \& Decker, 1979, p. 512). No estruturalismo interpretamos a resultante de uma cadeia diacrônica de elementos que ingressaram na estrutura no primeiro estado sincrônico.

As estruturas são não-causais. Não revelam a origem dos elementos nem o modo como operam, mas as condições, as formas de relações, que se definem por sua sintaxe, isto é, pelas leis de concordância, de subordinação e de ordem a que estão sujeitos os elementos. A prova do modelo é a sua eficácia explicativa.

À diferença de outras linhas de pensamento, como o marxismo e a fenomenologia, no estruturalismo o termo /estrutura/ é conceituado como algo inacessível à observação e à descrição observacional. O estruturalismo procura captar os fenômenos humanos aquém da consciência que deles se tem, escolhendo como terrenos de estudos privilegiados as ordens de fatos muito insignificantes e desprovidas de implicações práticas (Lévi-Strauss, 1971).

As estruturas são modelos de explicação (formas ontológicas). A propriedade que caracteriza uma estrutura não é inferida da abstração a partir dos objetos, mas da abstração reflexiva, como a do pensamento lógico-matemático (Piaget, 2003, p. 20). É próprio da abstração reflexiva ser tirada não dos objetos, mas das ações que se podem fazer sobre eles, tais como reunir, ordenar, corresponder. São operações de composição, de caráter dedutivo (construção apriorística) e não de indução (análise regressiva). Há estrutura quando os elementos estão reunidos em uma totalidade, apresentando algumas propriedades como totalidade e quando as propriedades dos elementos dependem, total ou parcialmente, dessas características de totalidade (Goldmann, 1979).

O estruturalismo considera a existência de estruturas superficiais (as que detectamos diretamente por observação) e estruturas profundas (as estruturas lógicas, que subjazem sob o aparente e o imediato) (Lévi-Strauss, 1958, p. 28). As últimas se reportam às primeiras. Por exemplo: a estrutura superficial do discurso está referida à estrutura profunda do conjunto de regras de linguagem. Cada estrutura superficial pode estar referida a várias estruturas profundas e cada estrutura profunda pode ser referência de várias estruturas superficiais. O número de estruturas profundas possíveis é limitado. Além disso, a estrutura tem 
propriedades finitas. Isto quer dizer que o número de relações é, também, logicamente limitado.

Duas ou mais relações formam uma estrutura quando pertencem a um mesmo plano, isto é são análogas - têm alguma afinidade, algum elemento comum entre si - e sincrônicas - coexistem no mesmo intervalo de tempo. A limitação do número e qualidade dos elementos e a limitação temporal permitem nos situarmos metodologicamente ante o vínculo que une diferentes elementos em um conjunto. Permitem operar com elementos e funções que extraem seu significado ${ }^{(2)}$ da referência uns dos outros e do conjunto que instituem e que podem dar lugar a uma formalização teórica (um modelo matematizável).

Uma estrutura compreende os caracteres de totalidade, de transformação e de auto-regulação (Piaget, 2003, p. 8; 12). Quer isto dizer que as estruturas são agregados totais, compostos a partir de elementos independentes do todo. Os elementos se subordinam a leis que caracterizam o sistema como tal ${ }^{(3)}$. De forma que o que conta é a relação entre os elementos (os processos de composição) que seguem leis (critérios) de inclusão. São, também, transformáveis mediante atividades estruturantes, que seguem leis imutáveis, como as da matemática e da lógica.

Evitando o associacionismo e as totalidades estáticas, dadas a priori, o estruturalismo propõe o estudo de conjuntos caracterizados pelas transformações solidárias em torno de um invariante (que caracteriza a estrutura). As transformações implicam um construtivismo de formação contínua, uma espiral que se alarga na medida em que nos aprofundamos na investigação (Piaget, 2003, p. 32). As estruturas, assim definidas, são auto-reguláveis no sentido da sua própria conservação, isto é, na exclusão dos elementos que não se enquadram nas leis que as caracterizam. A regulação pode ser ou não exercida por órgãos especializados (como, por exemplo, na biologia o sistema de transpiração, que serve para regular a temperatura do corpo).

\section{O Protocolo Mínimo}

O objeto do estruturalismo é o conjunto das relações interdependentes de fenômenos determinados. O referente da estrutura é o observado, o real concreto. $\mathrm{O}$ que não significa que a estrutura seja uma representação (uma figuração) da realidade. Significa, ao contrário, que uma estrutura bem construída representa logicamente as relações possíveis entre os elementos de um domínio psicossocial particular. 
O método consiste em ordená-los segundo uma perspectiva unificante. Ele está voltado para a identificação de um sistema relacional de elementos, das suas propriedades e do conjunto de estados e transformações possíveis pelos quais estes elementos e relações podem passar.

O estudo das propriedades consiste em examinar as condições que tornam possível à estrutura passar de um estado a outro, mediante a mudança de elementos, sem alterar o sistema estrutural. Essas passagens ou transformações assumem várias formas. Um exemplo clássico é o da transposição de uma melodia de tom para outro: todas as notas particulares podem ser alteradas, mas a melodia (a estrutura) permanece a mesma.

O estruturalista procura encontrar as totalidades. Não faz uso da análise e decomposição para encontrar os elementos supostamente últimos e determinantes. Pretende estabelecer a relação primeira da qual parte um ponto nodal - o que Roland Barthes (2000) denominou de /grau zero/ - não definido pelo seu conteúdo empírico, mas pelo fato de permitir ao conteúdo instituir-se em uma posição relacional. Barthes, buscou o grau zero da relação do escritor com a sociedade, Lévi-Strauss buscou o grau zero do parentesco e o do mito, Jakobson, o da língua, etc. (Dosse, 1993, p. 96).

\section{Escolha do Domínio Investigativo}

Os elementos do estruturalismo aplicados às ciências da gestão são análogos aos fonemas, aos mitemas ${ }^{(4)}$, aos elementos químicos, às notas musicais, etc. Os exemplos de unidades constituintes de estruturas no campo das organizações e da gestão são variados. Vão desde os nós nas cadeias logísticas até os papéis em um processo de negociação. Constituem estruturas as hierarquias, as formas de sociabilidade, as regras sociais, as mentalidades, os modos de dividir o trabalho, os modos de repartir a acumulação, os valores manifestos; os códigos, as normas, etc.

Os temas da análise estrutural contrastam com os de 20 anos atrás, como os relativos à dependência de recursos, à gestão de ativos e aos custos das transações. Neste início de século, a análise estruturalista tem sido praticada em estudos sobre desempenho \& racionalidade; sobre cultura organizacional e sobre produtividade \& trabalho ${ }^{(5)}$. Mas, praticamente, não existem limitações à aplicação do método estruturalista. Ele pode estar dirigido à elucidação da estrutura tanto de grupos elementares, entendidos como uma coleção de indivíduos, por exemplo, de empregados interdependentes que compartilham uma tarefa comum e que intercambiam para promover sua realização (derivam desse tipo de estudo as análises sobre as propriedades estruturais da liderança e sobre as estruturas (redes) 
de comunicação ${ }^{(6)}$ ) como da totalidade dos indivíduos em um conjunto de organizações.

O estudo das estruturas no campo organizacional e administrativo, como em qualquer campo particular, consiste em descrever um sistema relacional que possa ser identificado a partir de um ponto nodal que declare o significado do que subsiste para além do diretamente manifesto e o torne inteligível. Isto é feito mediante observação, decomposição em tipos de elementos, conceitualização dos elementos e relações, elaboração de um modelo genérico explicativo e de uma interpretação, que oferece a descrição da estrutura e das perspectivas explicativas e antecipatórias que encerra.

\section{Observação}

Ao procedermos à observação devemos ter sempre em mente que a origem da estrutura não é o real, mas o espírito humano. A intenção última não é a descrever o observado - este é apenas o primeiro dos passos metodológicos - mas a de encontrar o sentido próprio que está por trás das metáforas de elaboração (LéviStrauss, 1971).

A pesquisa empírica é apenas um ponto de partida, não uma âncora. O método estruturalista implica superar uma descrição direta do sensível (como no empiricismo), ou do vivido (como na fenomenologia), ou de uma gênese (como no historicismo). Esta superação se encontra na estrutura, na racionalidade que jaz além do empírico (Viet, 1973, p. 84).

Iniciamos a busca pelas estruturas mediante observação para não nos apartarmos da realidade concreta. Sabemos que não se trata de buscá-la nas relações submetidas à observação. Tampouco se trata de construir uma estrutura a priori, sem observação, para depois verificar se está estrutura se ajusta ao empírico.

Devemos observar o que existe e procurar isolar os elementos estáveis (sempre parciais) que permitem comparar e classificar (Lévi-Strauss, 1958, p. 356). Para isto, todos os fatos devem ser descritos com exatidão, em si mesmos; devemos cientificar-nos dos processos concretos que os produzem; em relação com o conjunto, devemos investigar o que o faz com que mudem e o que ocorre quando são alterados (Viet, 1973, p. 87).

Como disciplina, procuramos enfocar as resultantes (outputs) da atividade (social) do campo observado. Uma vez reconhecidas estas resultantes, identificamos as operações que as produzem. Por exemplo, podemos descrever uma estrutura de decisão considerando os elementos chave da decisão, os 
elementos secundários, os participantes, os interferentes, os não participantes do processo decisório, etc. Neste caminho, seguimos a orientação da antropologia que "para compreender os intercâmbios que regem o nascimento, o casamento, a iniciação ou a morte, despoja-os dos seus caracteres qualitativos, reduzindo-os a operações" (Claude Leford como citado em Viet, 1973, p. 86).

\section{Decomposição em Elementos}

Ao cabo do processo observacional, temos conjuntos de elementos factuais que se relacionam para produzir um determinado efeito ou situação. Estes elementos formam estruturas aparentes, das quais vamos buscar o fundamento, a estrutura subjacente.

Para isto, é necessário descodificar os seus elementos constituintes. Inicialmente os elementos devem ser definidos independentemente da sua articulação na estrutura. De outra forma cairemos em um círculo vicioso: o sentido dos elementos depende da relação em que está compreendido e a relação depende do sentido dos elementos. Devemos ser capazes de pensar o elemento de forma isolada, como conceito, o que não quer dizer que o elemento deva, necessariamente, existir isoladamente.

Listados os elementos, concluímos o passo de decomposição pela crítica dos resultados obtidos. Os elementos devem satisfazer as condições de serem: i) distintos, isto é, separáveis uns dos outros; ii) enumeráveis; iii) definíveis e, iv) claramente constantes ou claramente variáveis. Para integrarem a estrutura, os elementos devem ter uma classe de referência precisa, uma extensão definida e serem recorrentes em várias observações, como, por exemplo, a interdição (classe de referência) do incesto (extensão definida) é recorrente em muitas sociedades.

\section{Conceitualização dos Elementos}

Para que os elementos unidos por relações possam ser considerados estruturas, devem ser formalmente passíveis de substituição por signos, de modo que possamos aplicar-lhes raciocínios lógico-matemáticos. Os signos (termos, símbolos, representações) são conceitos cientifica e rigorosamente determinados. Devem se enunciados na forma: $\boldsymbol{x}$ entendido como $y$ (isto querendo dizer aquilo).

Ao conceitualizar os elementos, buscamos identificar as relações constantes que existem entre eles. O que significa que devemos tanto nos perguntar sobre os vínculos existentes entre os elementos (quais as relações?), como sobre a tipologia da relação considerada (por exemplo: jurídica, organizacional, social, histórica, geográfica, etc.) 
Os conceitos dos elementos isolados devem ser destacados e reagrupados enquanto "realização de pensamentos" (Benevistes, 1966, p. 64). Notemos que os signos (as palavras, os símbolos) que utilizamos para denotar os elementos das estruturas não representam a experiência do real, mas somente conceitos. Isto é, resultam de um esforço de elaboração e, portanto, são condicionados histórica e psicologicamente (Parain-Vial, 1972, p. 77).

\section{Elaboração do Modelo}

Uma estrutura é sempre a teoria de um sistema de aparências. Estuda a relação entre termos em seu caráter expositivo e diferencial. Por este motivo, a estrutura não pode ser apreendida diretamente na realidade concreta. É necessário estabelecer modelos teóricos que dêem conta dela.

Modelo é uma teoria específica sobre o comportamento de elementos de uma determinada classe. Por exemplo, enuncia a maneira em que os componentes de uma estrutura concreta se mantêm unidos. A noção de modelo do estruturalismo foi tomada da logística, dos modelos - descrições matemáticas do real desenvolvidos para enfrentar o Bloqueio de Berlim, mas é puramente formal, científica (Dosse, 1993, p. 200).

Um modelo científico é uma seqüência de entidades constituída na forma $\left(B_{1} \ldots, B_{\mathrm{n}}\left(A_{1} \ldots ., A_{\mathrm{n}}\right), R_{1} \ldots, R_{\mathrm{p}}\right)$ que satisfaz determinadas condições, sendo:

- a série $B$ representativa das proposições básicas;

- a série $A$ representativa das proposições secundárias e

- a série $R$ representativa das relações entre algumas dessas proposições.

Nos modelos quantitativos os conteúdos da série $R$ são grandezas. Nos modelos qualitativos são tipicamente relações classificatórias (conectivas, disjuntivas, etc.), relações de ordem (redes, seriações, correspondências) e relações topológicas (proximidade, continuidade, limite).

Os modelos lógico-matemáticos independem da realidade concreta. Os modelos das ciências factuais são construídos a partir de mensurações da realidade concreta. São submetidos a uma teoria geral em conjunto a proposições subsidiárias que os confirmam ou infirmam. Os modelos, no sentido em que o termo /modelo/ é empregado pelo estruturalismo, são construídos a partir de elementos observacionais, numéricos ou não. Servem para construir uma teoria das relações entre esses elementos: a estrutura.

A descrição dos elementos e dos sistemas relacionais nos dá modelos da 
realidade. São modelos conscientes, que ainda não são as estruturas. A análise estrutural tem como objeto os modelos inconscientes, implícitos. O modelo consciente não é uma estrutura. É um análogo. Ele é construído, isto é, ele não é uma visão do espírito, uma illuminatio (Piaget, 2003, p. 31). Serve como ponte entre o concreto (o dado, como o mito, a organização, a fala) e o inteligível (o construído, como a estrutura mítica, as formas de organizar, a língua). O modelo é que dá acesso à realidade, que nos ajuda a entender a estrutura profunda, não consciente.

A construção do modelo consiste nas seguintes operações:

1. definir o fenômeno em estudo como relação entre dois ou mais termos reais ou supostos;

2. construir uma tabela das permutas possíveis entre esses elementos;

3. proceder à análise, adotando esta tabela como referência, e considerando os fenômenos empíricos apenas como uma possível combinação entre outras, cujo sistema completo deve ser construído de antemão.

\section{Análise Interpretativa}

A interpretação estrutural parte dos modelos descritivos. Tais modelos podem ser mecânicos (relações simples) ou estatísticos. A análise estrutural consiste em: i) proceder a experimentações com os modelos, isto é, em realizar procedimentos que permitam saber como um modelo dado reage a modificações e, ii) a efetuar comparações entre modelos de mesmo tipo e de tipos diferentes. Com isto o modelo inconsciente, a estrutura, é construído racionalmente a partir da observação empírica. O caminho dessa construção consistindo, como vimos, em observar, extrair os elementos e as relações isoláveis e modelizar, isto é, em expor a estrutura sob a configuração de um esquema formal (simbólico) (Viet, 1973, p. 90).

Ao término do passo observacional tínhamos um modelo relacional concreto de um conjunto de elementos concretos. Ao término da interpretação estrutural devemos ser capazes de enunciar uma estrutura relacional formalizada de um conjunto determinado de elementos ordenados. A análise estrutural parte, portanto, da i) conceitualização dos elementos, isto é, a passagem do concreto ao formal (ao genericamente aplicável) e, ii) da análise interpretativa, isto é, a determinação dos elementos e das relações, para chegar a realizar uma construção lógica, isto é, uma ordenação estruturada dos elementos.

No esforço interpretativo nos voltamos para o exame das propriedades essenciais 
dos procedimentos, dos discursos, das segmentações, das interações, das técnicas, etc, constituintes das estruturas das quais o empírico e o aparente não passam de particularizações. Recusamos a descrição concreta do objeto (organizações, formas de organizar, maneiras de administrar). Concentramo-nos em encontrar os esquemas abstratos, anteriores à manifestação concreta das organizações e de gestão. Procuramos alcançar estruturas "naturais"(7), quer sejam as estruturas profundamente enraizadas na natureza humana, quer estruturas lógicas, independentes das variações temporais.

No estruturalismo, a lógica antecede a associação. Isto é, o estruturalismo sustenta que entendemos as associações mediante a lógica. É o contrário do positivismo, com o qual estamos mais afeitos, que sustenta que entendemos a lógica humana mediante associações. Por este motivo o modelo deve anteceder a análise. Não interessa ao estruturalismo, por exemplo, uma tipologia de organogramas, mas a determinação que nos faz dividir o trabalho segundo critérios determinados limitados (pela função, pelo produto, pelo tempo, pelo lugar e as demais distinções da organogramação).

Uma vez isolados os elementos e relações, devemos estabelecer as leis de composição do modelo. Tais leis devem ser gerais, porque sempre que as dimensões estruturais (planos / eixos de referência) ultrapassam certo limite, os métodos intuitivos já não funcionam. Como constatou Lévi-Strauss, “desde o momento em que a representação de um sistema exige um contínuo que ultrapassa três ou quatro dimensões, é impossível imaginá-lo" (Lévi-Strauss, 1962, p. 117).

O exemplo utilizado por Lévi-Strauss (1958, p. 303-352) para esclarecer sobre o processo de modelização é o do estudo do suicídio. Em um primeiro nível observacional, ele toma o suicídio da perspectiva dos casos individuais (mecânica). Considera a vítima, o meio, etc. Em um segundo nível, toma-o a partir do conjunto (estatística). Considera a freqüência dos suicídios em diferentes sociedades, em diferentes épocas, etc. Dessas relações extrai os modelos das várias formas de suicídio, do suicídio em sociedades diferentes, da relação entre o suicídio e outros fenômenos sociais etc. A analise estrutural compara os modelos entre si, procurando encontrar propriedades formais (leis, lógicas) que encerrem estruturas explicativas do fenômeno do suicídio em geral.

\section{Descrição}

A estrutura tanto se fundamenta nas relações sociais como as revela. Ela é um instrumento de explicação. Como tal, não considera a gênese das relações sociais e as vivências (a continuidade entre o vivido e o real da fenomenologia), mas o que ocorre efetivamente (o real) passível de descrição lógico-matemática. 
As formas de descrever as estruturas são variadas. Elas podem ser objeto de uma enunciação linear, ou de grafos, em que a representação dos elementos (vértices) ligados por linhas que denotam as relações. As conexões podem ser recíprocas ou orientadas, isto é, considerar o sentido em que se dá a conexão (setas). Podem vir sob a forma de matrizes referidas às correlações entre os elementos. Podem ser apresentadas como relações paritárias, como nos sociogramas, que retratam as diversas formas de sociabilidade, ou como relações hierárquicas, como nos organogramas, etc. $\mathrm{O}$ fundamental é que tenham sentido.

\section{Sentido}

Ter sentido quer dizer ter um significado lógico determinado. Os que torna a estrutura significativa é a forma como os seus elementos se relacionam, como a interdependência se manifesta. O sentido da estrutura é obtido atribuindo-se uma interpretação específica ao conjunto de elementos (referindo-os a algo) e à ordenação (enunciando a forma em que as relações constantes se dão). A estrutura é válida quando satisfaz a condição de explicar não só o observado, mas o observável. As estruturas identificadas e descritas devem ser capazes de autorizar o lançamento de novas hipóteses e de predições.

\section{Observações Finais}

Para concluir devemos ressaltar que o método estruturalista de investigação encerra dificuldades nada desprezíveis. Basta considerar que a sociedade não tem uma estrutura, mas uma multiplicidade delas - parentesco, código de etiqueta, maneiras de cozinhar, etc. - e que os sistemas simbólicos que formam a sociedade (organizações, linguagem, regras matrimoniais, relações econômicas, arte, ciência, religião) são imensamente diversos. Além disto, as estruturas podem conter contradições; podem ser ou não ser redutíveis umas às outras, podem ser incomensuráveis e a expressão de uma estrutura na outra pode estar deformada (torção) (Parain-Vial, 1972, p. 127).

A critica ao resultado do processo de elaboração das estruturas proposta por Lévi-Strauss (1958, p. 366) consiste, precisamente, em anular as torções e em encontrar uma homologia ideal. Podemos fazer isto via a elaboração de um protocolo de realização de testes empíricos ou de consistência lógica. Qualquer modalidade de comprovação empírica, paramétrica, não-paramétrica ou mesmo a simples documentação de ocorrências (caso) é válida para os fins a que o estruturalismo se propõe: demonstrar que a estrutura é possível. O protocolo de verificação define uma atividade operatória que permite fazer corresponder uma 
experiência precisa com os conceitos dos elementos simbolizados matematicamente. A verificação pode levar à validação ou à invalidação da estrutura, sendo que a validação pode ser empírica, ou, como no caso dos mitos, ser devida ao sentimento de inteligibilidade que aportam.

O método estruturalista exige rigor e diligência para que possa apresentar resultados. Mas não só por este motivo ele não vem sendo utilizado na frequiência e amplitude condizentes com as possibilidades de avanço do conhecimento que encerra. É que desde o seu surgimento ele sofre críticas sistemáticas oriundas tanto da direita, isto é do positivismo lógico, como da esquerda do pensamento cientifico, isto é, dos adeptos dos métodos historicistas. De um lado, questiona-se a demonstrabilidade das estruturas inconscientes. De outro, a não-consideração da gênese dessas estruturas. De forma que parece legitimo, para concluir este pequeno resumo do método do primeiro estruturalismo, apresentar a contraargumentação a estas críticas.

Alega-se, contra o estruturalismo, que as estruturas não podem ser demonstradas como universais, isto é, que não temos como saber, cientificamente, se o espírito (a racionalidade) é o mesmo para todos os seres humanos. O estruturalismo concorda que as subjetividades, por definição, são incomparáveis e incomunicáveis. Mas isto não leva à particularização da racionalidade. Ao contrário, argumentam os estruturalistas, se interagimos, como de fato o fazemos, é porque temos algo em comum para além da subjetividade, algo de que não temos consciência, isto é, uma vida mental cuja estrutura é compartilhada por toda a humanidade. A estrutura inata do espírito humano (Lévi-Strauss, 1973b).

A segunda linha de crítica contra o estruturalismo, de que abandona a gênese, a história dos fenômenos, que desconsidera as estruturas diacrônicas, não procede. Simplesmente o estruturalismo não nega a existência das estruturas diacrônicas (Lévi-Strauss, 1962, p. 40-45). Apenas afirma que não ser possível, nem útil, estudar ao mesmo tempo as estruturas e o seu processo evolutivo. A temporalidade vivida por um sujeito dentro de uma estrutura não pode ser captada e a perspectiva histórica só pode dar-se pela organização das condições conscientes. Além disto, o desenvolvimento histórico não é passível de descrição formal. Isto é, não é possível uma modelização lógico-matemática dos acontecimentos (Viet, 1973, p. 97) Por isso, o estruturalismo se concentra na estrutura inconsciente, qualquer que seja a sua situação no tempo e no espaço. Quando a estuda, estuda uma sincronia, para a qual a historicidade não é inexistente, mas é secundária.

O método estruturalista considera o objeto como totalidade passível de descrição a partir dos elementos que a constituem e das relações que mantém entre si. O estruturalismo, ao construir um método de análise formal, pretende dar objetividade ao estudo do humano. Ao destacar a dimensão sincrônica do objeto, possibilita a 
sua descrição enquanto entidade autônoma, facultando a emancipação dos estudos organizacionais e administrativos dos vínculos que os sujeitam às preocupações de outras ciências humanas e sociais. Em essência, leva à pratica do organizar e do administrar uma possibilidade concreta de teorização.

\section{Artigo recebido em 12.05.2004. Aprovado em 18.08.2004.}

\section{Notas}

${ }^{1} \mathrm{O}$ autor é grato ao Prof. Enrique Saravia e ao Pesquisador Roberto Pimenta, ambos da EBAPEFGV, pelas observações à versão inicial deste artigo.

${ }^{2}$ No sentido em que um mesmo termo pode ter significados diferentes. A palavra /time/ em inglês, significa tempo e hora. A palavra /tempo/ em português significa o equivalente a time (o tempo que transcorre); tense (o tempo verbal); weather (o tempo meteorológico).

${ }^{3}$ No sentido em que, por exemplo, os números primos têm propriedades estruturais diferentes das dos números pares e ambas as estruturas têm propriedades diversas das de um número (elemento) isolado.

${ }^{4}$ Unidades míticas mínimas paradigmáticas. O “desaninhador de aves” no mito Bororo, por exemplo.

${ }^{5}$ Para uma discussão ampla sobre a análise estruturalista na atualidade ver Lounsbury, 2003.

${ }^{6}$ Kurt Lewin (1965) procedeu a uma análise deste tipo. Procurou encontrar o equilíbrio dinâmico (equilíbrio quase estacionário) que faz com que a estrutura resista às forças que podem desintegrar os grupos.

${ }^{7}$ Natural no sentido em que são naturais os números inteiros positivos, que foram construídos por meio de operações tiradas da ação cotidiana (Piaget, 2003, p. 25).

\section{Referências Bibliográficas}

Barthes, R. (2000).

O grau zero da escrita: seguido de novos ensaios críticos (3a ed.). São Paulo: Martins Fontes.

Benveniste, É. (1966).

Problèmes de linguistique générale. Paris: Gallimard.
Blau, P.M., \&

Richard Scott, W. (1970).

Organizações formais. São Paulo:

Editora Atlas.

Bourdieu, P. (2001).

A economia das trocas simbólicas (5a ed.). São Paulo: Perspectiva. 
Bourdieu, P. (2002).

A profissão do sociólogo (3a ed.). Petrópolis: Vozes.

Caws, P. (1974, março).

Operational, representational, \& explanatory models. American Anthropologist, 76(1), 1-10.

Dosse, F. (1993).

História do estruturalismo (Vol. 2). São Paulo: Ensaio/Universidade Estadual de Campinas.

Etizioni, A. (1967).

Organizações modernas. São Paulo: Livraria Pioneira Editora.

Foucault, M. (1972).

A arqueologia do saber. Petrópolis: Vozes.

Foucault, M. (1979).

Microfísica do poder. Rio de Janeiro: Graal

Goldmann, L. (1979).

O conceito de estrutura significativa na história da cultura. In L. Goldmann (Ed.). Dialética e cultura. Rio de Janeiro: Paz e Terra. (Obra original publicada em 1958).

Hughes, J., \&

Sharrock, Y. (1999).

La filosofía de la investigación social (2a ed.). México: Fondo de Cultura Económica.

Jakobson, R. (1973).

Lingüística e comunicação. São Paulo: Cultrix.
Kronenfeld, D., \&

Decker, H. W. (1979).

Structuralism. Annual Review of Anthropology, 8, pp. 403-541.

Levi-Strauss, C. (1958).

Anthropologie structurale. Paris:

Plon.

Levi-Strauss, C. (1962).

Les limites de la notion de structure en ethonologie. In R. Bastide (Org.). Sens et usages du terme structure (pp. 40-45). Haya; Mouton.

Levi-Strauss, C. (1971).

[Entrevista de L'Express, 15 de março de 1971] [Les entretiens de L'Express]. L'Express, 1983.

Levi-Strauss, C. (1973a). Introduction à l'oeuvre de Marcel Mauss. In M. Mauss. Sociologie et anthropologie. Paris: P.U.F..

Levi-Strauss, C. (1973b).

Anthropologie structurale II. Paris: Plon.

Lewin, K. (1965).

Teoria de campo em ciência social. São Paulo: Pioneira

Lounsbury, M., \&

Ventresca, M. (2003, August).

The new structuralism in organizational theory. Organization, 10(3), 457-480.

Mauss, M. (1968).

Oeuvre. Paris: Éditions de Minuit.

Parain-Vial, J. (1972).

Análisis estructurales e ideologías estructuralistas. Buenos Aires: Amorrurtu Editores. 
Parsons, T. (1960).

Structure and process in modern societies. Glencoe, Illinois: The Free Press.

Piaget, J. (2003).

O estruturalismo. Rio de Janeiro: DIFEL

Runciman, W. G. (1969, September). What is structuralism? The British Journal of Sociology, 20(3) 253-265.
Teixeira, I. (1998, outubro).

Estruturalismo. In Cult:Revista Brasileira de Literatura,(15), pp.3437.

Viet, J. (1973).

Los métodos estructuralistas en las ciencias sociales. Buenos Aires: Amorrurtu Editores. (Obra original publicada em 1967). 